ISSN 2077-8333 (print)

ISSN 2311-4088 (online)

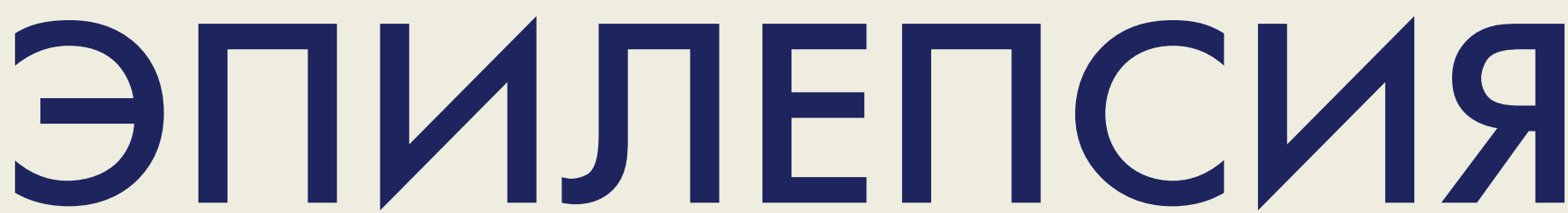

и пароксизмальные

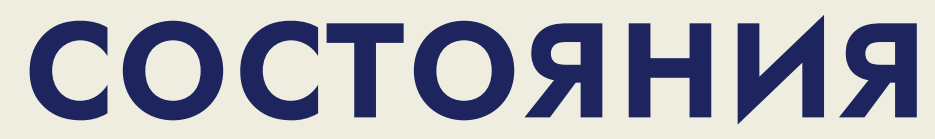

2020 Том 12 №2

EPILEPSY AND PAROXYSMAL CONDITIONS

2020 Vol. 12 №2
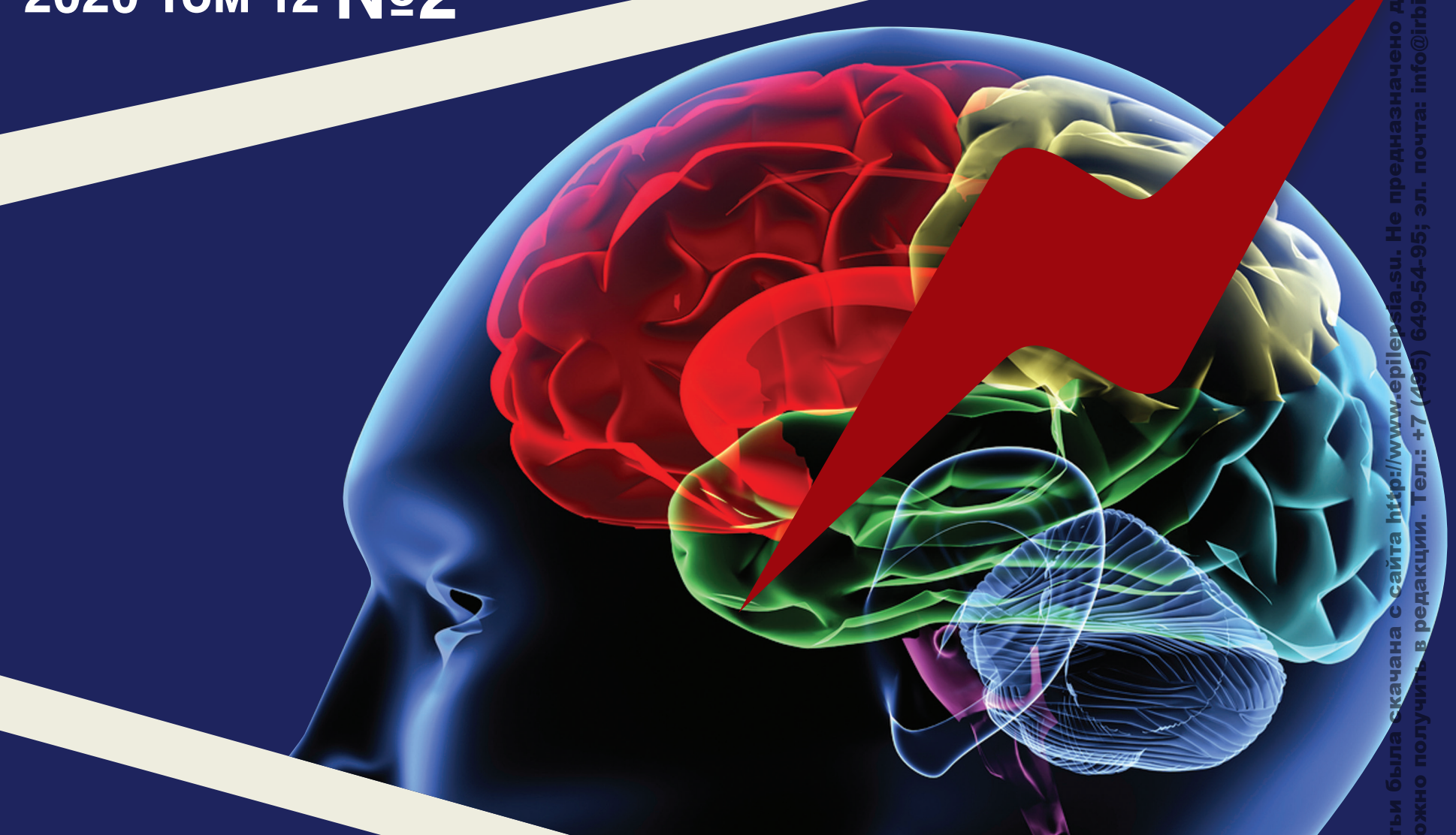

www.epilepsia.su 


\section{Эпилептический миоклонус}

Миронов М.Б.', Бурд С.Г.,2, Рублева Ю.В.', Красильщикова T.M. ${ }^{2}$, Таирова P.T. ${ }^{1}$

1 Федеральное государственное бюджетное учреждение «Федеральный центр мозга и нейротехнологий» Федерального медико-биологического агентства (ул. Островитянова, д. 1, стр. 10, Москва 117997, Россия)

2 Федеральное государственное автономное образовательное учреждение высшего образования «Российский национальный исследовательский медицинский университет им. Н.И. Пирогова» Министерства здравоохранения Российской Федерации (ул. Островитянова, д. 1, Москва 117997, Россия)

Для контактов: Миронов Михаил Борисович, e-mail: mironovmb@mail.ru

\section{PEЗЮME}

Представлены основные дефиниции, классификация и электроклинические характеристики эпилептического миоклонуса.

\section{КЛЮЧЕВЫЕ СЛОВА}

Эпилепсия, эпилептический миоклонус, миоклонические приступы, фрокальный миоклонус, негативный миоклонус.

Статья поступила: 28.05.2020 г.; в доработанном виде: 18.06.2020 г.; принята к печати: 30.06.2020 г.

\section{Конфликт интересов}

Авторы заявляют об отсутствии конфликта интересов в отношении данной публикации.

Все авторы сделали эквивалентный вклад в подготовку публикации.

\section{Для цитирования}

Миронов М.Б., Бурд С.Г., Рублева Ю.В., Красильщикова Т. М., Таирова Р. Т. Эпилептический миоклонус. Эпилепсия и пароксизмальные состояния. 2020; 12 (2): 122-124. https://doi.org/10.17749/2077-8333/epi.par.con.2020.030.

\section{Epileptic myoclonus}

Mironov M.B. ${ }^{1}$, Burd S.G. ${ }^{1,2}$, Rubleva Yu.V. ${ }^{1}$, Krasilshchikova T.M. ${ }^{2}$, Tairova R.T. ${ }^{1}$

${ }^{1}$ Federal Center for Brain and Neurotechnologies of the Federal Medical and Biological Agency (1-10 Ostrovityanova Str., Moscow 117997, Russia)

2 Pirogov Russian National Research Medical University (1 Ostrovityanova Str., Moscow 117997, Russia)

Corresponding author: Mikhail B. Mironov, e-mail: mironovmb@mail.ru

\section{SUMMARY}

The article presents the main definitions, classification, and electroclinical characteristics of epileptic myoclonus.

\section{KEY WORDS}

Epilepsy, epileptic myoclonus, myoclonic seizures, focal myoclonus, negative myoclonus.

Received: 28.05.2020; in the revised form: 18.06.2020; accepted: 30.06.2020.

\section{Conflict of interests}

The authors declare the absence of conflict of interest with respect to this publication.

All authors contributed equally to this article.

For citation

Mironov M.B., Burd S.G., Rubleva Yu.V., Krasilshchikova T.M., Tairova R.T. Epileptic myoclonus. Epilepsia i paroksizmal'nye sostoania/ Epilepsy and Paroxysmal Conditions. 2020; 12 (2): 122-124 (in Russ.). https://doi.org/10.17749/2077-8333/epi.par.con.2020.030. 
Согласно предложениям комиссии Международной противоэпилептической лиги миоклонус называют эпилептическим только в тех случаях, когда он возникает в сочетании с кортикальными эпилептиформными разрядами (ILAE, 1997). Эпилептический миоклонус (ЭМ) является обобщающим названием разных приступов различного генеза.

В рамках ЭМ выделяют следующие типы приступов (ILAE, 1997):

- первично-генерализованные миоклонические приступы;

- миоклонические приступы в рамках феномена вторичной билатеральной синхронизации на электроэнцефралограмме (ЭЭГ);

- ЭМ век;

- фокальный ЭМ;

- негативный миоклонус (фокальные атонические приступы).

ЭМ следует дифференцировать с некоторыми схожими состояниями (ILAE, 1997). К ним относятся немиоклонические эпилептические приступы, в т.ч. эпилептические спазмы, которые более продолжительны, нередко возникают в виде кластеров и синхронны с разрядом «медленная волна» на ЭЭГ высокой амплитуды. Также их следует отличать от тонических приступов, связанных с низкоамплитудной быстроволновой активностью на ЭЭГ. Некоторые эпилептические приступы являются двухфазными, включая миоклонически-атонические, миоклонический с переходом в спазм или спазм с переходом в тонический приступ.

Отдельно выделяют неэпилептический миоклонус, включая синдром opsoclonus myoclonus, при котором миоклонус является почти непрерывным, неустойчивым и индуцированным движением. Доброкачественный миоклонус сна может возникать у здоровых новорожденных или младенцев. Кроме того, его возникновение чаще, чем у других пациентов, возможно у новорожденных с церебральным параличом, вызывая нарушения сна, частые пробуждения. Миоклонус может появляться при прогрессирующей дистонии, обычном испуге. К неэпилептическим, немиоклоническим состояниям, в частности, относится тремор, при котором сокращение поочередно воздействует на мышцы-агонисты и антагонисты, является более ритмичным, чем миоклонус. Тики длятся 200 мс, и частота может быть изменена добровольно. При хорее частота разрывов нерегулярна, составляет 50750 мс и асинхронна в мышцах-антагонистах.
Согласно дефиниции Международной противоэпилептической лиги генерализованные миоклонические приступы определяются как внезапные, короткие (<100 мс) непроизвольные одиночные или множественные сокращения мышц или групп мышц с вариабельной локализацией: аксиальной, проксимальной, дистальной мускулатуры, мышц туловища (Scheffer I. с соавт., 2017). При этом миоклонические приступы сопровождаются короткими диффузными разрядами комплексов полипик-волна на ЭЭГ (ILAE commission report, 1997).

Данный тип приступов может входить в структуру многих форм эпилепсий и эпилептических синдромов, нередко диаметрально противоположных по прогнозу в отношении течения заболевания, неврологическим и когнитивным нарушениям, «набору» эпилептических приступов и ответу на противоэпилептическую терапию (Карлов В. А., 2019).

ЭМ век с абсансами или без - тип ЭМ, проявляющийся миоклониями век. В редких случаях ЭМ век может сочетаться с абсансными пароксизмами. На ЭЭГ синхронно с ЭМ век выявляется характерный паттерн возникновение эпилептиформной активности при закрывании глаз. Эпилептиформные разряды при этом возникают в первые 1-3 с после закрывания глаз.

ЭМ век может входить не только в структуру идиопатических (генетических) генерализованных форм эпилепсии, в частности при синдроме Дживонса, но также обнаруживается и при структурной фокальной эпилепсии с феноменом вторичной билатеральной синхронизации, а также нередко регистрируется в рамках синдрома Драве (Миронов М.Б. с соавт., 2016).

Фокальный ЭМ - фокальные эпилептические миоклонические приступы, возникающие вследствие локальных эпилептиформных разрядов в сенсомоторной коре головного мозга (ILAE Commission Report. Myoclonus and Epilepsy in Childhood, 1997). Клинически фокальный ЭМ может быть активным или негативным (Caviness J., 2013; Guerrini R., Takahashi T., 2013; Shiraishi H. с соавт., 2013).

Данный тип приступов входит в структуру тяжелых, как правило, резистентных к терапии эпилептических синдромов: Кожевниковской эпилепсии, энцефалита Расмуссена, прогрессирующих миоклонус-эпилепсий и др. (Мухин К. Ю. с соавт., 2011; Котов А. С. с соавт., 2009; Panayiotopoulos C., 2012; Bien C., 2008).

\section{Сведения об авторах:}

Миронов Михаил Борисович - к.м.н., ведущий научный сотрудник отдела эпилепсии и пароксизмальных состояний ФГБУ «Федеральный центр мозга и нейротехнологий» ФМБА России. ORCID ID: https://orcid.org/0000-0003-4844-8042; Author ID: 632779; РИНЦ SPIN-код: 1144-7120; E-mail: mironovmb@mail.ru.

Бурд Сергей Георгиевич - д.м.н., профессор кафедры неврологии, нейрохирургии и медицинской генетики лечебного факультета ФГБОУ ВО РНИМУ им. Н.И. Пирогова Минздрава России; руководитель отдела эпилепсии и пароксизмальных состояний ФГБУ «Федеральный центр мозга и нейротехнологий». ORCID ID: https://orcid.org/0000-0003-0804-7076.

Рублева Юлия Владимировна - к.м.н., старший научный сотрудник эпилепсии и пароксизмальных состояний ФГБУ «Федеральный центр мозга и нейротехнологий»; заведующая отделением неврологии №1 ФГБУ «Федеральный центр мозга и нейротехнологий» ФМБА. ORCID ID: https://orcid.org/0000-0002-3746-1797. 
Красильщикова Татьяна Михайловна - ассистент кафедры неврологии, нейрохирургии и медицинской генетики педиатрического фракультета ФГБОУ ВО РНИМУ им. Н.И. Пирогова Минздрава России. ORCID ID: https://orcid.org/0000-0002$5864-4867$.

Таирова Раиса Таировна - к.м.н., заместитель директора по лечебной работе, главный врач ФГБУ «ФЦМН» ФМБА России. ORCID ID: https://orcid.org/0000-0002-4174-7114.

\section{About the authors:}

Mikhail B. Mironov - MD, PhD, Leading Researcher, Department of Epilepsy and Paroxysmal Conditions, Federal Center for Brain and Neurotechnologies of the Federal Medical and Biological Agency. ORCID ID: https://orcid.org/0000-0003-4844-8042; Author ID: 632779; РИНЦ SPIN-код: 1144-7120; E-mail: mironovmb@mail.ru.

Sergey G. Burd - MD, Dr Sci Med, Professor at the Department of Neurology, Neurosurgery and Medical Genetics, Faculty of Pediatrics, Pirogov Russian National Research Medical University; Head of the Department of Epilepsy and Paroxysmal Conditions, Federal Center for Brain and Neurotechnologies of the Federal Medical and Biological Agency. ORCID ID: https:// orcid.org/0000-0003-0804-7076.

Yulia V. Rubleva - MD, PhD, Senior Researcher for Epilepsy and Paroxysmal Conditions, Federal Center for Brain and Neurotechnologies of the Federal Medical and Biological Agency. ORCID ID: https://orcid.org/0000-0002-3746-1797.

Tatyana M. Krasilshchikova - MD, Assistant, Chair of Neurology, Neurosurgery and Medical Genetics, Faculty of Pediatrics, Pirogov Russian National Research Medical University, Ministry of Health of the Russian Federation. ORCID ID: https://orcid. org/0000-0002-5864-4867.

Raisa T. Tairova - MD, PhD, Deputy Director for Medical Work, Chief Physician of the Federal State Budgetary Institution, Federal Center for Brain and Neurotechnologies of the Federal Medical and Biological Agency. ORCID ID: https://orcid.org/00000002-4174-7114. 